accredited academic module in Specialist Palliative and End of Life Care, in partnership with the local university and investigating the role of apprenticeships for hospice Healthcare Support Workers and Assistant Practitioners.

\section{P-285 WHAT INFLUENCES PALLIATIVE CARE NURSES IN THEIR CHOICE TO ENGAGE IN OR DECLINE CLINICAL SUPERVISION?}

${ }^{1}$ Nick Puffett, ${ }^{2}$ Paul Perkins. 'Independent Clinical Supervisor, Cheltenham UK; ${ }^{2}$ Sue Ryder, Cheltenham, UK

\subsection{6/bmispcare-2017-hospice.310}

Background Clinical Supervision has been around since the early 1990s in the UK and has been endorsed by government and professional bodies. Levels of engagement range from 18\%-85\% (Butterworth et al., 2008).

Aim To investigate what influences palliative care nurses in their choice to engage in or decline clinical supervision.

Methods A qualitative study was undertaken in an in-patient hospice in England and employed two focus groups to compare the views of participants and non-participants in clinical supervision. Data was audio recorded and transcribed verbatim by the researchers and analysed using Systematic Text Condensation (Malterud, 2012).

Results Palliative care nurses all used informal team support for 'in the moment' support. Some engaged in formal clinical supervision to reflect 'on action' and to challenge practice. Nurses reported a lack of clarity regarding clinical supervision but, once this was overcome and engagement with clinical supervision was established, it led to changes in practice, identification of training needs and team building. Options of group and individual supervision were found to be important. Group supervision led to enhanced understanding of group members which also led to team building, individual sessions were useful for individual issues. Protected time was essential for staff to be able to engage in clinical supervision. Staff who worked in larger teams reported higher levels of engagement whereas a small team reported less need due to more informal team support. The interview themes allowed development of a Palliative Care Nurses Model of Support.

Conclusions Nurses need to be aware of their options for support and ultimately how this affects the care they provide. The Palliative Care Nurses Model of Support helps to explain the effects of each choice and how this may lead to teambuilding.

\section{P-286 USING OSCES WITH INPATIENT CLINICAL STAFF TO MAINTAIN CLINICAL COMPETENCE}

Toni Flanagan, Angie Greenwood. St Giles Hospice, Lichfield, UK

10.1136/bmjspcare-2017-hospice.311

Hospice nurses require a range of clinical skills to meet the varying needs of their patients. These skills ensure safe, effective and timely care, however, there can be limited exposure in clinical practice therefore Observed Structured Clinical Examinations (OSCE) were introduced at St Giles Hospice as a way of bridging this gap. An OSCE is a simulated assessment used widely in healthcare education (Hensler, 2013) and is recognised nationally as a model for evaluating clinical competencies (McWilliam \& Botwinski, 2014). Preparing and conducting an OSCE is resource-intensive (Ahuja, 2009) and can provide some evidence of competence (Hensler, 2013) especially in environments where clinical learning opportunities can be limited (McWilliam \& Botwinski, 2014).

Four OSCE subjects were chosen and performance criteria devised. These criteria were then available for the participating registered nurses. The participating nurses were given two months' notice of the date of assessment. The standard operating procedures for each skill and additional resources were also made available for the participating nurses prior to the assessments. Thirty minutes was allocated for each skill which included time for feedback.

The registered nurses who took part in the OSCEs were asked to complete a questionnaire one month after. Overall both the examiners and participating registered nurses found the OSCEs to be a positive experience; they helped to increase confidence, acted as a refresher and highlighted areas for further learning on a personal and team level. However, it is important to remember that performance in the simulated environment may not be easily transferred to the clinical environment (Hensler, 2013). Following these OSCEs, the performance criteria have been split into procedure and knowledge to better identify where further learning is required. It was also decided that OSCEs would be implemented annually and also incorporate Health Care Assistants.

\section{P-287 BUILDING ON COMPETENCY}

Colin Twomey, Tara Schrikker, Ruth Bacon, Susan Stocks, Eirian Levell. St Wilfrid's Hospice (Eastbourne), UK

\subsection{6/bmispcare-2017-hospice.312}

Background The hospice has a well-established competency framework for Registered Nurses and Healthcare Assistants which guides staff progression. The importance of developing capabilities of the hospice workforce has been well documented (Help the Hospices, 2012). The hospice's Nursing and Care Quality Forum recognised the importance of creating further growth opportunities for those who had achieved the most experienced level of competence whilst engaging staff in continuous practice development.

Aims To ensure an engaged and motivated group of staff working together to progress practice development across the hospice. The programme formed the next stage in the cycle for those who had completed the competencies at the highest level for their role and recognised the need to embed continuous quality improvement whilst providing on-going career development.

Methods A two-year programme was designed. The first year consisted of facilitated monthly sessions covering broad skills related topics. The second year required staff to work with colleagues on a particular project aimed at improving patient care and experience. Eleven Registered Nurses and 13 Healthcare Assistants have participated. In addition, participants attend regular facilitated sessions to ensure on-going support and engagement. Participants self-assessed their confidence and competence at the beginning of the programme to allow evaluation of its impact after completion.

Results The second year has produced increased engagement from staff who have worked together on specific areas of practice development. The areas include: bowel assessment; 